\title{
Effect of diabetes on occurrence of urinary tract infection and asymptomatic bacteriuria among diabetic and ketacidosis patients in Egypt
}

\author{
N.N. Adly, Y.M. Ragab, A.M. Hashem, A.K. Ahmady \\ Cairo University Egypt \\ Corresponding author's E-mail:Nermin_Nader@hotmail.com
}

\begin{abstract}
Diabetic patients have a higher risk of infections which is the leading trigger of diabetic ketoacidosis. The second most common infection in diabetics is urinary tract infection (UTI). Elevation of glucose level induces an inflammatory process within numerous tissues in the body leading to disturbance in cytokines level and oxidative stress. This study is divided into two parts, firstly it was to investigate the prevalence of asymptomatic bacteriuria (ASB) and urinary tract infections in 84 Type 1 diabetes patients, 63 Type 2 diabetes patients and 57 ketoacidotic patients, and to determine the uropathogens responsible for ASB and UTIs as well as their antimicrobial susceptibility pattern. The second part is to determine the level of IL-1 $\beta$, IL- 6 and superoxide dismutase (SOD) in blood samples of diabetic and ketoacidotic patients. Escherichia coli was the most common isolated bacterial uropathogen followed by Enterococcus faecalis, Staphylococcus saprophyticus and Pseudomonas aeruginosa. These isolates showed $100 \%$ sensitivity to cephalothin, imipenem, linezolid, teicoplanin, ceftobiprole and piperacillin-tazobactam. Upon examining cytokines level in diabetic patients, results showed higher levels of IL- $1 \beta$ and IL- 6 than control samples, indicating inflammation and disturbance in the regulation of metabolic, regenerative, and neural processes, while SOD examination showed lower levels than control samples, indicating both micro- and macrovascular diabetic complications.
\end{abstract}

Keywords: Urinary tract infection, asymptomatic bacteriuria, diabetes, IL-1 $\beta$, IL-6, superoxide dismutase.

\section{INTRODUCTION}

Diabetes has interested medical authors for over 3 millenia since the ancient Egyptians who discovered this disease in 1862 AD (Poretsky, 2002). According to WHO, diabetes mellitus is the ninth leading cause of death worldwide. Good diabetes management has been shown to reduce the risk of complications (Stratton et al., 2000) otherwise it may lead to microvascular and macrovascular damage (King et al., 1999) as well as microbial infections (Joshi et al., 1999) especially urinary tract infection (Chiţă et al., 2013), accounting for

nearly $25 \%$ of all infections in the elderly and affecting mainly children and women (Buonanno and Damweber, 2006). Hirji et al. (2012a) reported a $60 \%$ increase in the risk of urinary tract infection in diabetic patients. UTI is of great concern since it is considered as a precipitating factor of diabetic ketoacidosis (DKA) together with pneumonia (Koul, 2009). DKA can be developed in less than 24 hours and it is the most severe acute metabolic complication of diabetes mellitus (Umpierrez et al., 1996) as it causes $70 \%$ of diabetes-related fatalities (Flaws, 2002). Elevation of glucose level induces an inflammatory process within numerous tissues in the body (Wellen and Hotamisligil, 2005). Therefore, cytokines reflect the presence and intensity of inflammation, and they have long been used as a clinical guide to diagnosis and management (Gabay, 2006). The main cytokines involved in the pathogenesis of diabetes as well as ketoacidosis are IL-1, TNF- $\alpha$, and IL-6 (Alexandraki et al., 2006; Stewart, 2006). Interleukin 1 (IL-1), is a key mediator of inflammation (Mandrup-Poulsen, et al., 2010) while IL-6 plays roles in the immune system and inflammation (Guzmán et al., 2010).

Oxidative stress may constitute the key and common event in the pathogenesis of secondary diabetic 
complications (Moussa, 2008). It occurs due to both hyperglycemia (de Carvalho Vidigal et al., 2012) and ketosis (Jain and McVie, 1999). Superoxide overproduction is considered as a major pathogenic pathway in diabetic vascular complications (Brownlee, 2005).

SOD is the major antioxidant enzyme for superoxide removal, (Vaziri et al., 2003), and the front line for defense against reactive oxygen species (ROS) (Apel and Hirt, 2004).

The aim of this study was firstly to determine uropathogenic pattern and UTI percentage in urine samples obtained from T1DM, T2DM and ketoacidotic patients as well as the antibiotic sensitivity patterns of the pathogens concerned. The second aim was to determine the level of IL-1 $\beta$, IL-6, and SOD in blood samples obtained from the three mentioned groups; T1DM, T2DM and ketoacidotic patients.

\section{METHODOLOGY}

This study was done on three groups of patients' type 1 diabetes mellitus (T1DM), type 2 diabetes mellitus (T2DM) and DKA patients.

\section{Bacteriological urine samples analysis}

\section{Samples collection}

A total of 84 urine samples of T1DM patients and 57 samples of ketoacidotic patients were collected from children department and intensive care unit in National Diabetes \& Endocrinology Institute- Kasr El Ainy- Cairo, Egypt, respectively. A number of 63 samples of T2DM patients were collected from a private clinical laboratory, Giza. Urine samples were obtained by clean voided midstream technique or from urethral catheter as in case of DKA patients.

\section{Urine analysis and microscopy}

Urine samples collected were tested by dipstick method for glucose in T1DM and T2DM patients, and for both glucose and ketones in ketoacidotic patients. Each sample was tested microscopically for pus cells and for the initial count of organism by pour plate technique. Samples showing pyuria and bacteriuria as well as positive urine glucose test in T1DM, T2DM patients and positive urine glucose and ketone test in ketoacidotic patients were subjected to a sequence of identification steps.

\section{Biochemical investigation}

One $\mathrm{ml}$ of each selected sample was added to each of lactose broth and trypticase soya broth. After incubation for $24 \mathrm{hr}$ at $37^{\circ} \mathrm{C}, 0.1 \mathrm{ml}$ from the lactose broth was streaked on MacConkey agar and $\mathrm{EMB}$, and $0.1 \mathrm{ml}$ from trypticase soya broth was streaked on Mannitol salt agar, Cetrimide agar, Nutrient agar and Sabouraud dextrose agar + chloramphenicol. After incubation at $37^{\circ} \mathrm{C}$ for 24 $\mathrm{hr}$, growing organism was checked for colony morphology, gram reaction and motility, then subjected to a sequence of identification tests including: catalase, oxidase, coagulase, indole, methyl red, VogesProskauer, triple sugar iron, germ tube, citrate utilization test, urease test, and novobiocin sensitivity test.

\section{Antibiotic sensitivity tests}

Each isolated organism was tested for antibiotic sensitivity according to Kirby Bauer method (Bauer et al., 1966). Tested antibiotics included: Ampicillin $10 \mu \mathrm{g}$, Ampicillin+Sulbactam 10/10 $\mu \mathrm{g}$, Piperacillin $100 \mu \mathrm{g}$, Cefepime $30 \mu \mathrm{g}$, Aztreonam $30 \mu \mathrm{g}$, Imipenem $10 \mu \mathrm{g}$, Meropenem $10 \mu \mathrm{g}$, Vancomycin $30 \mu \mathrm{g}$, Norfloxacin 10 $\mu \mathrm{g}$, Ofloxacin $5 \mu \mathrm{g}$, Gentamicin $10 \mu \mathrm{g}$, Linezolid $30 \mu \mathrm{g}$, Methicillin $5 \mu \mathrm{g}$, Cefaclor $30 \mu \mathrm{g}$, Oxacillin $1 \mu \mathrm{g}$, Cloxacillin $5 \mu \mathrm{g}$, Cefotaxime $30 \mu \mathrm{g}$, Penicillin $10 \mathrm{U}$, Amoxicillin 25 $\mu \mathrm{g}$, Teicoplanin $30 \mu \mathrm{g}$, Cephalothin $30 \mu \mathrm{g}$, Cefalexin 30 $\mu \mathrm{g}$, Cefadroxil $30 \mu \mathrm{g}$, Ciprofloxacin $5 \mu \mathrm{g}$, Piperacillin + tazobactam 100/10 $\mu \mathrm{g}$, Polymixin B $300 \mathrm{U}$, Erythromycin $15 \mu \mathrm{g}$ and Clindamycin $2 \mu \mathrm{g}$ that were all obtained from Bioanalyse Co. (Turkey). Ceftobiprole $30 \mu \mathrm{g}$, Novobiocin $5 \mu \mathrm{g}$, Voriconazole $1 \mu \mathrm{g}$, Fluconazole $25 \mu \mathrm{g}$ and Nystatin $100 \mathrm{U}$ were obtained from Becton Dickinson (USA).

\section{Immununological assay of IL-1 $\beta$, IL-6, and SOD in Serum by ELISA}

\section{Samples collection}

Blood samples were collected from patients of T1DM, T2DM and ketoacidotic patients for serum level assay of IL-1 $\beta$, IL-6, and superoxide dismutase (SOD) by the use of ELISA. Samples were collected from T2DM patients at diabetes clinic, El Kasr El Ainy hospital. T1DM blood samples were collected from Diabetes and Endocrinology department as well as Abo El Reesh pediatric hospital. DKA blood samples were collected from intensive care unit of Diabetes and Endocrinology department and Abo El Reesh pediatric hospital.

\section{Samples immunoassay}

Each sample collected from the groups of volunteers was tested first for blood glucose by Accucheck blood glucose test strips. Normal control blood samples were collected from Abo El Reesh pediatric hospital and Kasr El Ainy 
Table 1. Mean age of the study population

\begin{tabular}{lcccc}
\hline Type of patients & No. & Mean age \pm SD & Minimum & Maximum \\
\hline T1DM & 84 & $10 \pm 4$ & 4 & 18 \\
T2DM & 63 & $54 \pm 6$ & 42 & 67 \\
DKA & 57 & $37 \pm 17$ & 11 & 62 \\
\hline
\end{tabular}

Urine analysis result

Table 2. Distribution of UTI cases in diabetic patients.

\begin{tabular}{lccc}
\hline Number of samples/ percentage & T1DM & T2DM & DKA \\
\hline Total number of samples collected & 84 & 63 & 57 \\
Number of male /female of samples collected & $48 / 36$ & $34 / 29$ & $36 / 21$ \\
Total number of infected samples/ percentage & $54 / 64.28 \%$ & $49 / 77.77 \%$ & $42 / 73.68 \%$ \\
Number of male infected samples/ percentage & $24 / 44.4 \%$ & $27 / 55.1 \%$ & $26 / 61.9 \%$ \\
Number of female infected samples/ percentage & $30 / 55.5 \%$ & $22 / 44.8 \%$ & $16 / 38 \%$ \\
\hline
\end{tabular}

hospital laboratory and checked for negative blood glucose test by Accucheck blood glucose strips. The quantitative determination of Interleukin-1 $\beta, \mathrm{IL}-6$, and SOD concentrations in serum was done according to the method stated by the kit manufacturer, ANOGEN (Mississauga, Ontario, Canada) for IL-1 $\beta$ and IL-6, and IBL International (Hamburg, Germany) for SOD.

\section{RESULTS}

\section{Bacteriological assay}

\section{Sampling design}

During the study period, clean-catch urine samples were obtained by mid-stream method from T1DM patients, T2DM patients and from ketoaicdotic patients. Table 1 shows the number of submitted UTI cases from each diabetes type with their age mean, SD, minimum and maximum age.

\section{Total aerobic microbial count and pyuria results}

As shown in table 2, out of 84 T1DM patients, 54 patients $(64.28 \%)$ showed positive urine culture with bacteriuria and pyuria. Out of 63 T2DM patients, 49 patients $(77.77 \%)$ showed positive urine culture and pyuria. Out of the 57 ketoacidotic patients, 42 patients $(73.68 \%)$ showed positive urine culture and pyuria. The prevalence of UTI in female (30\%) was higher than male (24\%).

\section{Identification of bacterial isolates}

Isolated bacterial strains from urine samples were examined phenotypically for gram reaction, cell shape, culture description, and biochemical tests according to Bergey's manual (1994) and Koneman's Color Atlas and Textbook of Diagnostic Microbiology (2006). Finally, API was used for confirmation if needed. Out of 145 isolated strains, 68 were gram positive bacteria, 71 strains were gram negative and yeast strains represented in Candida albicans were detected in 6 samples. Figure 1 shows that the most frequently isolated uropathogens were Escherichia coli, followed by Enterococcus faecalis, Staphylococcus saprophyticus, Pseudomonas aeruginosa and Staphylococcus aureus

\section{Antibiotic susceptibility testing}

Susceptibility of gram negative isolatesAs shown in figure 2, Escherichia coli showed $100 \%$ sensitivity to cephalothin (first generation cephalosporin) and imipenem, while its least sensitivity was to norfloxacin. Klebsiella pneumoniae exhibited the highest sensitivity to 
30 Int. Res. J. Microbiol.

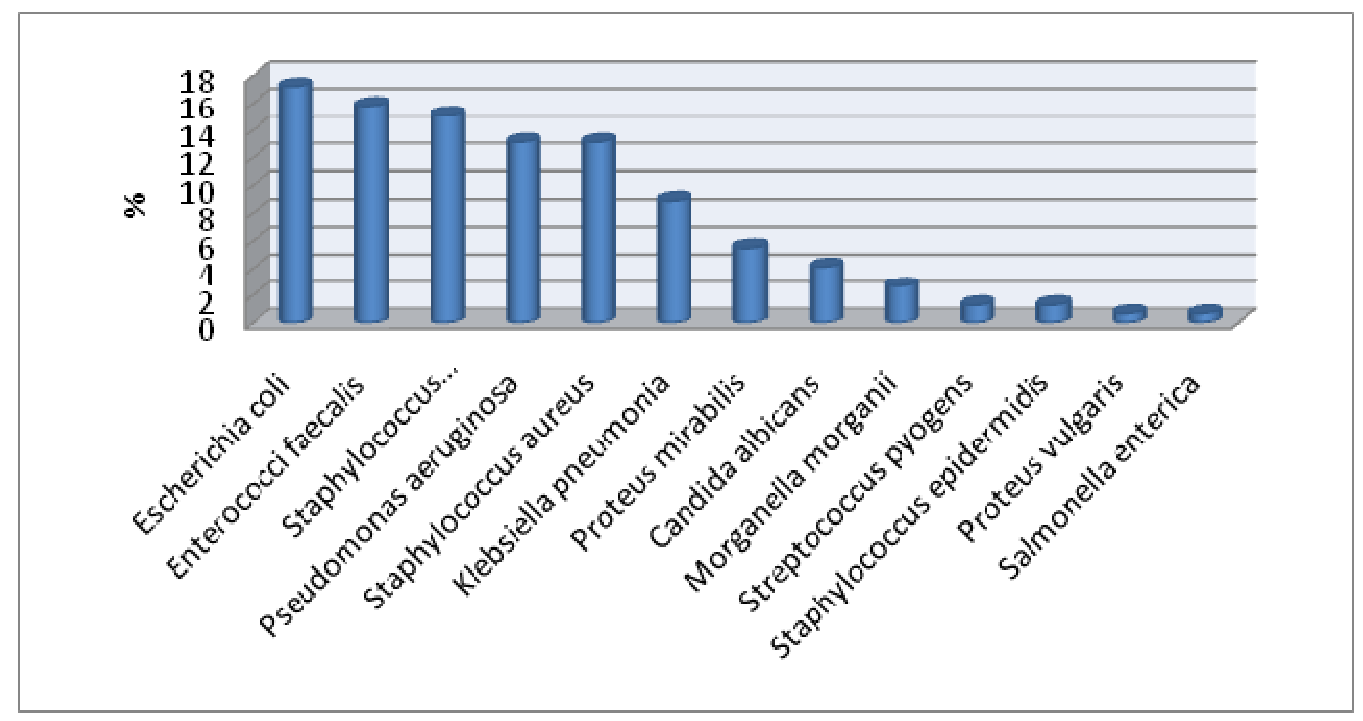

Figure 1. Frequency of uropathogenic isolates among diabetic patients.

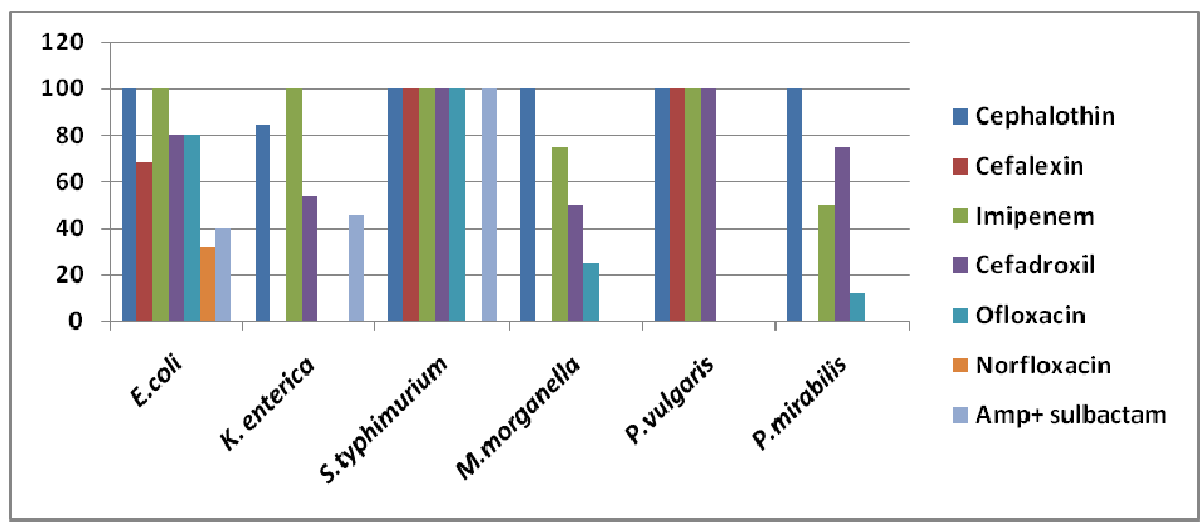

Figure 2. Antibiotic sensitivity pattern of Enterobacteriacae.

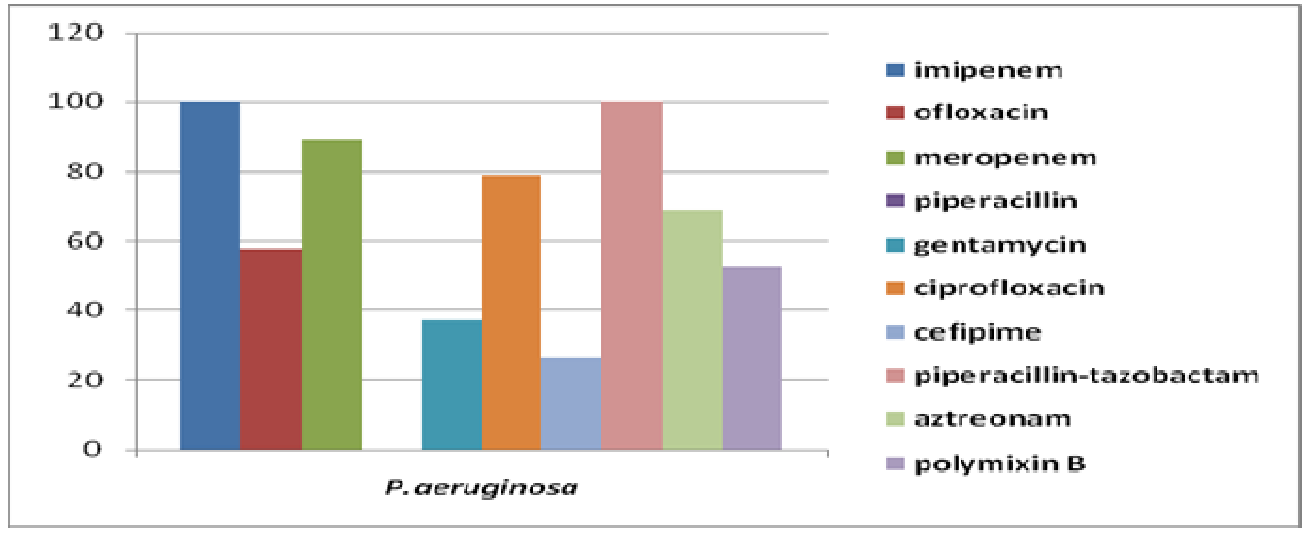

Figure 3. Antibiotic sensitivity pattern of Pseudomonas aeruginosa.

imipenem with percentage $100 \%$, however, all strains were resistant to cefalexin, ofloxacin and norfloxacin.
Salmonella was unique in being sensitive to all tested antibiotics except norfloxacin. As for Morganella its 


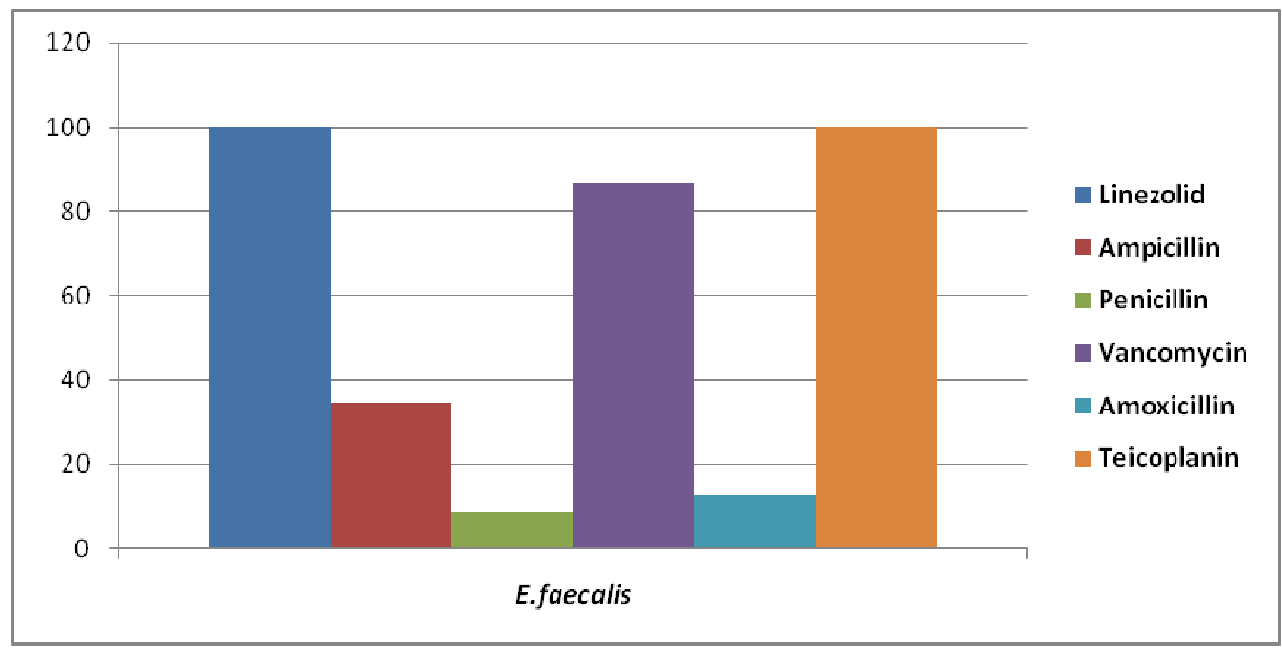

Figure 4. Antibiotic sensitivity pattern of Enterococcus faecalis

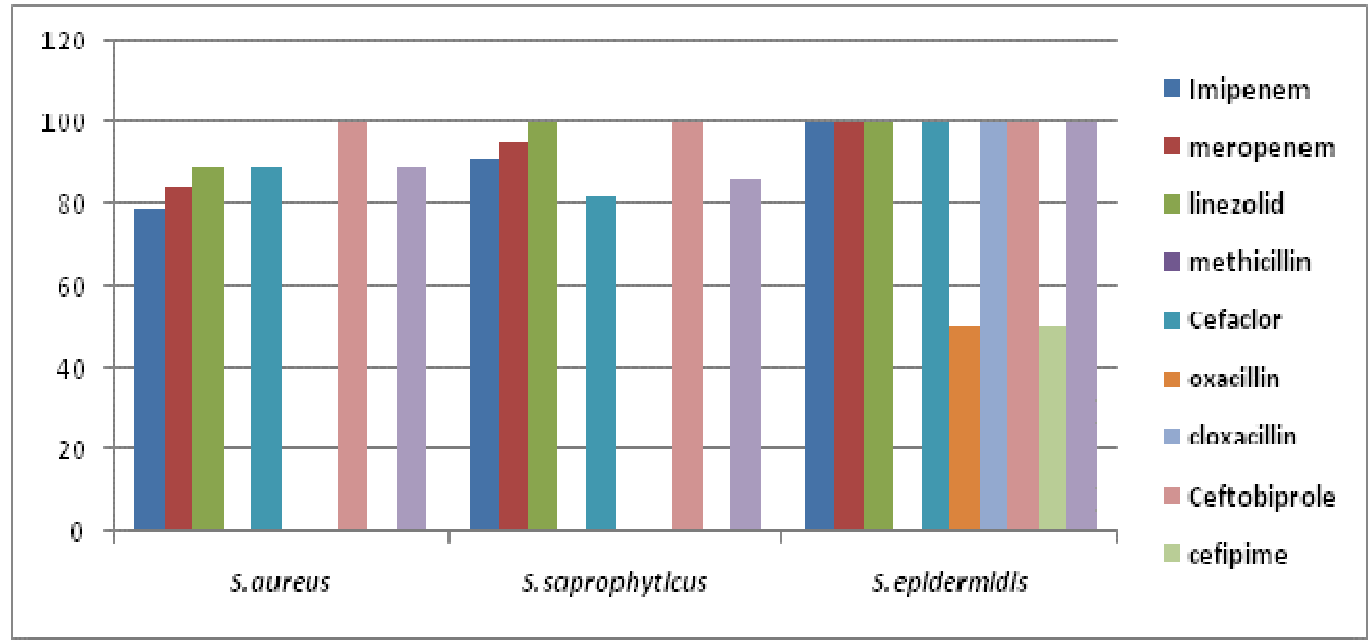

Figure 5. Antibiotic sensitivity pattern of Staphylococcus spp

highest sensitivity was to cephalothin with a percentage of $100 \%$, while all strains were resistant to cefalexin, norfloxacin, and ampicillin / sulbactam with a percentage of $100 \%$.

Proteus vulgaris was $100 \%$ sensitive to cephalothin, cefalexin, imipenem, and cefadroxil, meanwhile it was $100 \%$ resistant to the other antibiotics. Proteus mirabilis showed $100 \%$ resistance to cephalothin, while it showed full resistance to cefalexin, norfloxacin and ampicillin + sulbactam.

Pseudomonas aeruginosa exhibited $100 \%$ sensitivity to piperacillin-tazobactam and imipenem while it showed $100 \%$ resistance to piperacillin. The least sensitivity was exhibited to gentamycin and cefepime (fourth generation cephalosporin) with a percentage of $36.8 \%$ and $26.3 \%$, respectively.

\section{Susceptibility of gram positive isolates}

Data presented in figures 6 and 7 illustrate that Staphylococcus aureus showed $100 \%$ sensitivity to ceftobiperole (fifth generation cephalosporin). As for linezolid, cefaclor (second generation cephalosporin), and cefotaxime (third generation cephalosporin) it showed the same sensitivity to them with a percentage of $89.4 \%$. However, all Staphylococcus aureus strains were $100 \%$ resistant to methicillin, oxacillin, cloxacillin, and cefipime (fourth generation cephalosporin).

Staphylococcus saprophyticus showed $100 \%$ sensitivity to ceftobiprole and linezolid but 100\% resistance to methicillin, oxacillin, cloxacillin, and cefipime.

All Staphylococcus epidermidis strains were sensitive 


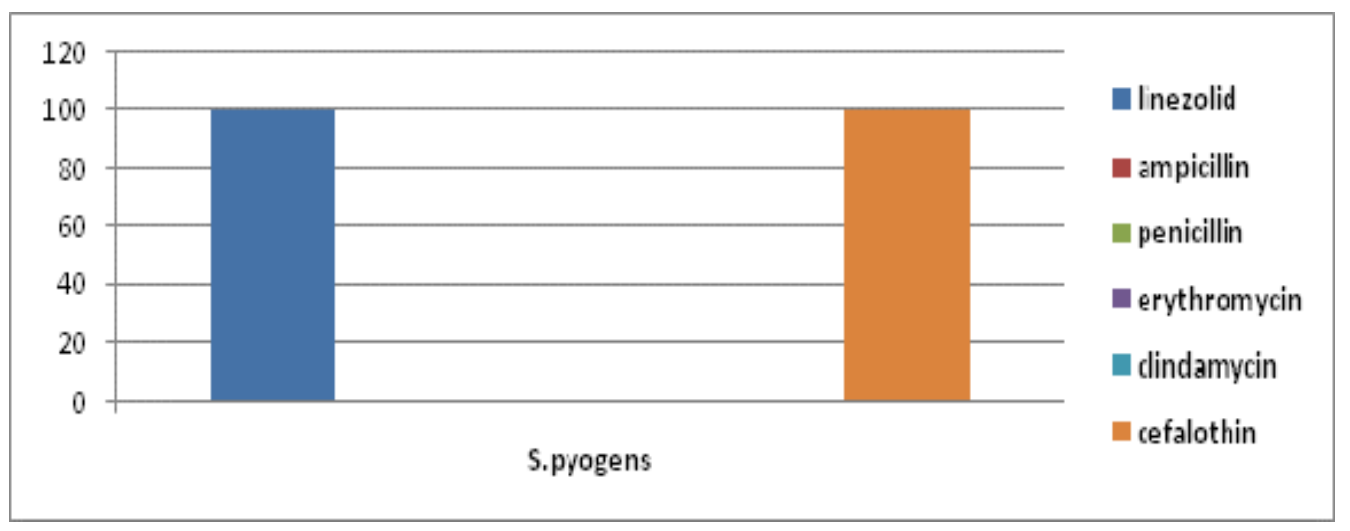

Figure 6. Antibiotic sensitivity pattern of Streptococcus pyogenes.

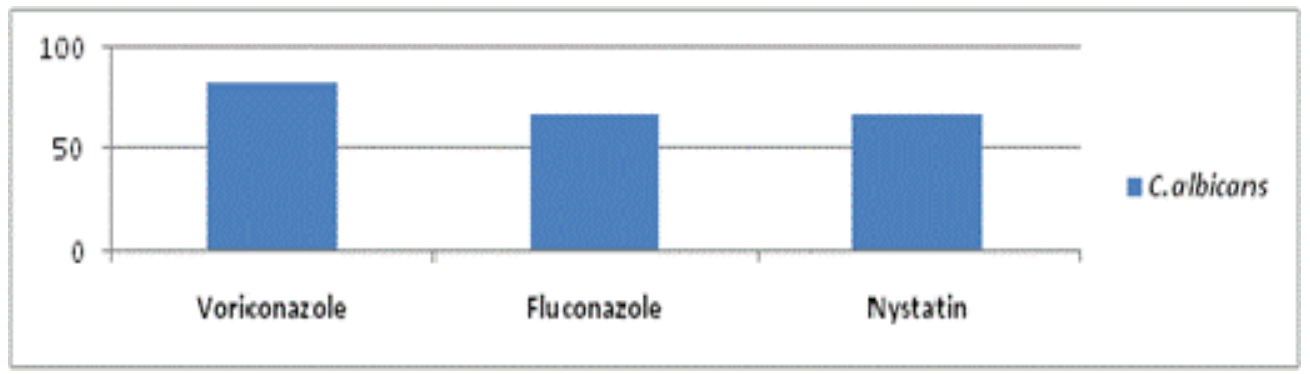

Figure 7. Antifungal sensitivity pattern of Candida albicans

to imipenem, meropenem, linezolid, cefaclor, cloxacillin, ceftobiprole, and cefotaxime. Its sensitivity to oxacillin and cefipime was $50 \%$, while it was $100 \%$ resistant to methicillin.Enterococcus faecalis was $100 \%$ sensitive to teicoplanin and linezolid followed by vancomycin with a percentage of $86.9 \%$. It showed very low sensitivity to penicillin and amoxicillin (8.7 and $13 \%$, respectively).

Streptococcus pyogenes showed $100 \%$ sensitivity to linezolid and cephalothin while it showed 100\% resistance to ampicillin, penicillin, erythromycin and clindamycin.

In conclusion, among the gram negative isolates Salmonella typhimurium showed the highest sensitivity to the tested antibiotics, while among the gram positive, Staphylococcus epidermidis was the most sensitive. On the other hand, Proteus vulgaris was the most resistant gram negative isolate while the gram positive isolates Staphylococcus aureus, Staphylococcus saprophyticus and Enterococcus faecalis had in parallel the same resistance level to tested antibiotics.

\section{Yeast isolates}

As shown in figure 7, Candida albicans sensitivity to voriconazole was greater than for both fluconazole and nystatin with a percentage of $83.4 \%$.

\section{Cytokines immunological assay}

The same letter means that there is no significant difference between the two groups by using Duncan multiple comparison test at $p<0.05$. The different letters mean that there is a significant difference between the two groups by using Duncan multiple comparison test at $\mathrm{p}<0.05$.

A significant difference was observed by using One Way Anova at $P<0.05$ between the five groups in IL-1 $\beta$, IL-6 and SOD analysis as shown in table 3.By using Duncan multiple comparison test at $\mathrm{P}<0.05$ in the analysis of each of IL-1 $\beta, I L-6$ and SOD, there is a significant difference between normal control I and Type I diabetes, normal control I and DKA, DKA and Type I diabetes, as well as between normal control II and Type II diabetes.

Table 4 was constructed to identify that the value of 5.19 was the best cut-off point to predict response of IL$1 \beta, 5.8$ for IL- 6 and 0.16 for SOD. IL- $1 \beta$ of 5.19 or more provided a sensitivity of $98 \%$, and a specificity of $100 \%$. IL-6 of 5.8 or more provided a sensitivity of $100 \%$ and a 
Table 3. Study population of diabetic patients compared to controls.

\begin{tabular}{|c|c|c|c|c|c|c|c|c|}
\hline Parameter & Group & $\mathbf{N}$ & Minimum & Maximum & Mean & S.D & F-value & p-value \\
\hline \multirow{5}{*}{ Age } & Normal control group II & 10 & 27 & 58 & $42.50^{b}$ & 10.61 & \multirow{5}{*}{12.93} & \multirow{5}{*}{$0.000^{*}$} \\
\hline & Type 2 & 20 & 25 & 58 & $42.05^{\mathrm{b}}$ & 9.07 & & \\
\hline & DKA & 20 & 3 & 15 & $8.45^{\mathrm{a}}$ & 3.47 & & \\
\hline & Type 1 & 20 & 4 & 14 & $8.45^{\mathrm{a}}$ & 3.02 & & \\
\hline & Normal control group I & 10 & 5 & 19 & $12.00^{b}$ & 4.85 & & \\
\hline \multirow{5}{*}{ Duration } & Normal control group II & 10 & - & - & - & - & \multirow{5}{*}{8.60} & \multirow{5}{*}{$0.001^{*}$} \\
\hline & Type 2 & 20 & 1 & 25 & $8.60^{\mathrm{b}}$ & 7.58 & & \\
\hline & DKA & 20 & 1 & 7 & $3.20^{\mathrm{a}}$ & 1.85 & & \\
\hline & Type 1 & 20 & 1 & 8 & $3.45^{\mathrm{a}}$ & 1.96 & & \\
\hline & Normal control group I & 10 & - & - & - & - & & \\
\hline \multirow{5}{*}{ IL-1 B } & Normal control group II & 10 & 1.9 & 5.1 & $3.30^{\mathrm{a}}$ & 1.05 & \multirow{5}{*}{20.13} & \multirow{5}{*}{$0.035^{*}$} \\
\hline & Type 2 & 20 & 10.8 & 22.6 & $16.24^{\mathrm{C}}$ & 3.18 & & \\
\hline & DKA & 20 & 16.8 & 24.1 & $20.15^{\mathrm{C}}$ & 2.24 & & \\
\hline & Type 1 & 20 & 5.1 & 9.2 & $7.39^{\mathrm{b}}$ & 1.33 & & \\
\hline & Normal control group I & 10 & 1.9 & 4.2 & $2.94^{\mathrm{a}}$ & 0.81 & & \\
\hline \multirow{5}{*}{ IL6 } & Normal control group II & 10 & 2.3 & 4.3 & $3.52^{\mathrm{a}}$ & 0.75 & \multirow{5}{*}{25.49} & \multirow{5}{*}{$0.016^{*}$} \\
\hline & Type 2 & 20 & 13.4 & 22.3 & $18.33^{\mathrm{C}}$ & 2.73 & & \\
\hline & DKA & 20 & 17.9 & 26.2 & $22.04^{c}$ & 2.42 & & \\
\hline & Type 1 & 20 & 5.9 & 11.9 & $9.19^{b}$ & 1.50 & & \\
\hline & Normal control group I & 10 & 2.6 & 5.8 & $3.87^{\mathrm{a}}$ & 0.91 & & \\
\hline \multirow{5}{*}{ SOD } & Normal control group II & 10 & 16 & 0.24 & $0.19^{d}$ & 0.02 & \multirow{5}{*}{39.68} & \multirow{5}{*}{$0.000^{*}$} \\
\hline & Type 2 & 20 & 0.06 & 0.19 & $0.13^{b}$ & 0.03 & & \\
\hline & DKA & 20 & 0.01 & 0.16 & $0.08^{a}$ & 0.07 & & \\
\hline & Type 1 & 20 & 0.09 & 0.21 & $0.16^{\mathrm{c}}$ & 0.03 & & \\
\hline & Normal control group I & 10 & 0.17 & 0.23 & $0.20^{\mathrm{d}}$ & 0.02 & & \\
\hline
\end{tabular}

S.D = Standard Deviation

${ }^{*}=$ There is a significant difference by using One Way ANOVA at $p<0.05$

Table 4. The best cut-off point, sensitivity and specificity of IL-1 $\beta$, IL-6 and SOD

\begin{tabular}{lccccc}
\hline Parameter & Cut-off point & Sensetivity & Specificity & A.U.C & p-value \\
\hline IL-1B & $>5.19$ & 98.33 & 100 & 1 & $0.0001^{*}$ \\
IL-6 & $>5.8$ & 100 & 100 & 1 & 1 \\
SOD & $>0.16$ & 81.67 & 95 & 0.95 & $0.0001^{*}$ \\
\hline
\end{tabular}

* $=$ Significant at $p<0.001$.

specificity of $100 \%$. SOD of 0.16 or more provided a sensitivity of $81.67 \%$ and a specificity of $95 \%$.

\section{DISCUSSION}

Urinary tract infection is a common medical problem; sometimes, leading to deaths either from acute infection or from chronic renal failure (Khadka et al., 2012). Risk of UTI is higher with increasing duration of diabetes (Boyko et al., 2005). High urine glucose content and defective host immune factors predispose to infection. Hyperglycemia causes neutrophil dysfunction by increasing intracellular calcium levels and interfering 
with act in and, thus, diapedesis and phagocytosis. Also this may contribute to malfunctioning in the local urinary cytokine secretion and an increased adherence of bacteria to the cells of the uroepithelial cells (Saleem and Daniel, 2011). Vaginal candidiasis and vascular disease also play a role in recurrent infections (Brusch and Bronze, 2013).

A high prevalence of ASB (71\%) was recorded in this study. This value is higher than that reported in other studies ranging from 19 to $47.2 \%$ (Baqai et al., 2008; Longdoh et al., 2013; Simkhada, 2013).

The study showed that males are more vulnerable to pathogenic attack than females throughout a wide age distribution. In terms of pathogenic distribution, E. coli was the most commonly recovered uropathogen with a percentage of $17.2 \%$ which is the least recorded prevalence among other studies ranging from 30.8 to $83.7 \%$ (Hryniewicz et al., 2001; Bonadio et al., 2006; Simkhada, 2013).

Enterococcus faecalis was the second most isolated uropathogen with a percentage of $15.8 \%$ which is obviously higher than other studies ranging from 1.7 to $9.52 \%$ (Hryniewicz et al., 2001; Longdoh et al.,2013; Simkhada, 2013).

Staphylococcus saprophyticus had a prevalence of $15.1 \%$ being less than that reported by Baskar et al. (2009) (55\%). Pseudomonas aeruginosa and Staphylococcus aureus had the same prevalence with a percentage of $13.1 \%$ which was higher than that obtained in other studies where Pseudomonas aeruginosa prevalence was found to range from 2.5 to $9.52 \%$ (Hryniewicz et al., 2001; Ramana and Chaudhury, 2012; Longdoh et al., 2013; Simkhada, 2013).

Staphylococcus aureus prevalence was higher than that reported by Ramana and Chaudhury (2012) and lower than that found by Longdoh et al., (2013).

The least prevalence among G+ve bacteria was for Staphylococcus epidermidis $(1.3 \%)$ as well as Streptococcus pyogenes which is lower than that reported by Longdoh et al. (2013). Among G-ve bacteria both Proteus vulgaris and Salmonella enterica had the least prevalence with percentage $0.68 \%$.

These high percentages refer to the fact of being commensal bacteria colonizing the gastrointestinal tract (Franz and Horl, 1999) as well as referring to virulence factors related to these uropathogens. One of the most important virulence mechanisms in urinary tract infections is adherence which is an initial step in the infectious process for successful establishment of infection by bacterial pathogens which requires adhesion to host cells, this is done by adherence factor. Its importance also refer to its role in adhering to urinary catheter or other implants especially in case of hospitalized patients (nosocomial pathogens). Cell adhesion molecules includes pili as possessed by E.coli (Nagamatsu et al., 2015) and Klebsiella pneumoniae (Murphy et al., 2013), adhesins as used by Staphylococcu s saprophyticus
(Kline et al., 2010), Enterococcus faecalis (Nielsen et al., 2013) and Proteus mirabilis (Armbruster and Moble, 2015), MSCRAMMs of staphylococcus aureus (Costa et al., 2013), Extracellular DNA Exopolysacchariddes in Pseudomonas aeruginosa (Cole et al., 2014).

Urease is also a well-known virulence factor for a number of bacterial pathogens including, Proteus spp. (Armbruster, and Moble, 2015), staphylococcus saprophyticus (Kline et al., 2010), Klebsiella spp. (Brisse $\mathrm{S}$ et al., 2006). It is essential for pathogenic bacteria to colonize in host and in maintenance of bacterial cells in tissues, having for toxic effect due to its enzymatic activity. Antimicrobial resistance among uropathogens causing community- and hospital-acquired UTIs is increasing (Bonadio et al., 2001). Upon investigating the susceptibility pattern of enterobacterial isolates with different antibiotics they showed high sensitivity rate with a percentage of $100 \%$ with cephalothin unlike data obtained by Sahm et al. (2001) who found $86.6 \%$ resistance. For Pseudomonas aeruginosa, its highest sensitivity was shown to piperacillin/ tazobactam with percentage $100 \%$ which is in contrast to data obtained by Mokaddas and Sanyal, (1999) (14\%).

On the other hand, Staphylococcus isolates showed highest sensitivity rate with percentage $100 \%$ to ceftobiprole which is similar to the observations of Bogdanovich et al., (2005). Enterococcus faecalis showed $100 \%$ sensitivity to teicoplanin which is the same as found by Rudy et al., (2004). Streptococcus pyogenes exhibited $100 \%$ sensitivity to linezolid in accordance with that found by Cercenado et al. (2001). All isolates were also sensitive to cephalothin unlike the data of Longdoh et al. (2013) who reported a sensitivity percentage of $55 \%$ to similar cephalosporins. Candida albicans showed high sensitivity to voriconzole with a percentage of $83.4 \%$ followed by fluconazol and nystatin with a percentage of $66.6 \%$. This sensitivity to azoles was higher than that reported by longdoh et al. (2013) which was $28 \%$, while sensitivity to nystatin was lower than that reported by the same authors (72.3\%). In conclusion, the high ASB percentage observed in this study is of major public health importance since it is a leading cause to diabetic ketoacidosis which is together with hyperglycemic coma the most severe acute metabolic complication of diabetes mellitus (Umpierrez et al., 1996).

Circulating IL-6, TNF- $\alpha$, and CRP have been determined as markers of the inflammatory response (Davi et al., 2003). Chemokines play a central role in inflammatory processes by regulating leukocyte migration into sites of tissue damage (Erbagci et al., 2001). The proinflammatory cytokines, IL-1 $1 \beta$, IL- 6 , and TNF- $\alpha$ have cytotoxic, cytostatic (inhibits insulin synthesis and secretion) or cytocidal actions to pancreatic islets by inducing nitric oxide (NO) production (Tchorzewski et al., 2001). IL-1beta is a regulator of the body's inflammatory response and is produced after infection, injury and antigenic challenge (Maedler et al., 2009). In this study, 
IL-1 $\beta$ was examined randomly among Type 1 diabetes mellitus, Type 2 diabetes mellitus and ketoacidotic patients. Plasma levels of IL-1 $\beta$ in patients submitted were higher than control group which is a similar finding to that reported by Javed and Ahmed (2013). In the present study, the mean plasma level of IL-1 $\beta$ was nearly three, seven and five times the control group value in Type 1 diabetes mellitus, ketoacidotic and Type 2 diabetes mellitus patients, respectively.

IL-6 is reported to have multiple effects ranging from inflammation to host and tissue injury (Santhanam et al., 2003). It is known to increase inflammation and the development of vascular disease and atherosclerosis (Jain et al., 2003). IL-6 plasma levels were examined in Type 1 diabetes mellitus, Type 2 diabetes mellitus, and ketoacidotic patients blood, and the obtained values were significantly higher than control group plasma levels. These data were in accordance with other study by Wegner et al. (2013). In contrary Dogan et al. (2006) found that IL-6 was lower in diabetic patients. Several complications of diabetes mellitus are associated with increased activity of free radicals and accumulation of lipid peroxidation products (Prakash and Sudha, 2012). Numerous reports indicate variations in the levels of antioxidants in diabetic patients (Lee et al., 1995). This is due to decreased activity of antioxidant enzymes which increase the susceptibility of diabetic patients to oxidative injury. In this study, the level of SOD in the three groups of patients was lower than that of control group. This observation is in line with other study by Prakash and Sudha (2012), however, Moussa (2012) observed a significant increase in SOD levels in another study. Based on the above data as well as the ROC curve in this study, we can conclude that IL-1 $\beta, I L-6$ and SOD are sensitive markers for diabetes complication.

\section{REFERENCES}

Alexandraki K, Piperi C, Kalofoutis C, Singh J, Alaveras A and Kalofoutis A (2006). The inflammatory process in type 2 diabetes. The role of cytokines. Ann N Y Acad Sci. 1084: 89-117.

Apel k, Hirt H (2004). Reactive Oxygen Species: Metabolism, Oxidative Stress, and Signal Transduction. Annu. Rev Plant Biol. 55: 373399.

Armbruster CE, Mobley HL (2012). Merging mythology and morphology: the multifaceted lifestyle of Proteus mirabilis. Nature Rev. Microbiol. 10: 743-754.

Baqai R, Aziz M, Rasool G (2008). Urinary tract infections in diabetic patients and biofilm formation of uropathogens. Infect. Dis. J. Pak. 17: $21-24$.

Baskar NV, Sivakumari V, Arun Kumar S, Senthil Kumar S (2009). Isolation, Identification And Antimicrobial Susceptibility Of Organisms Cause Urinary Tract Infection In Diabetic Patients And Young Children's. Advanced Bio tech. 9: 24-26.

Bauer AW, Kirby WMM, Sherris JC, Turck M (1966). Antibiotic susceptibility testing by a standardized single disk method. Amer. J. Clin. Pathol. 45: 493-496.

Bogdanovich T, Ednie LM, Shapiro S, Peter CA (2005). Antistaphylococcal Activity of Ceftobiprole, a New Broad- Spectrum Cephalosporin. Antimicrobial Spectrum Cephalosporin. Antimicrobial agents chemotherapy. 49: 4210-4219.
Bonadio M, Meini M, Spitaleri P, Gigli C (2001). Current microbiological and clinical aspects of urinary tract infections. Eur Urol. 40(4): 43944

Bonadio M, Costarelli S, Morelli G, Tartaglia T (2006). The influence of diabetes mellitus on the spectrum of uropathogens and the antimicrobial resistance in elderly adult patients with urinary tract infection. BMC Infectious Diseases. 6: 54.

Boyko EJ, Fihn SD, Scholes D, Abraham L, Monsey B (2005). Risk of urinary tract infection and asymptomatic bacteriuria among diabetic and nondiabetic postmenopausal women. Am. J Epidemiol. 161 : $557-564$.

Brisse S, Grimont F, Grimont PD (2006). The Genus Klebsiella. Prokaryotes. 6:159-196.

Brownlee M (2005). The pathobiology of diabetic complications: a unifying mechanism. Diabetes.54: 1615-1625.

Brusch JL, Bronze MS (2013). Urinary Tract Infections in Diabetes Mellitus. Medscape.

Buonanno AP, Damweber BJ (2006). Review of Urinary Tract Infection. US Pharm . 31: 06

Cercenado E, Garrcia-Garrote and Bouza E (2001). In vitro activity of linezolid against multiply resistant Gram-positive clinical isolates. J. of antimicrobial chemotherapy. 47: 77-81.

Chiţă T, Licker M, Sima A, Vlad A, Timar B, Sabo P, Timar R (2013). Prevalence of urinary tract infections in diabetic patients. Rom $\mathrm{J}$ Diabetes Nutr Metab Dis. 20: 099-105.

Cole SJ, Records AR, Orr MW, Linden SB, Lee VT (2014). Catheterassociated urinary tract infection by Pseudomonas aeruginosa is mediated by exopolysaccharide-independent biofilms. Infect. Immun. 82: 2048-2058.

Costa AR, Batistão DWF, Ribas RM , Sousa AM , Pereira MO, Botelho CM (2013). Staphylococcus aureus virulence factors and disease Formatex. 1: 702-710.

Davi G, Chiarelli F, Santilli , Pomilio M, Vigneri S, Falco A, Basili S, Ciabattoni G, Patrono C (2003). Enhanced lipid peroxidation and platelet activation in the early phase of type 1 diabetes mellitus: role of interleukin-6 and disease duration. Circulation. 107: 3199-3203.

De Carvalho VF, Guedes CP, Gonçalves PL, de Cássia GAR (2012). The role of hyperglycemia in the induction of oxidative stress and inflammatory process. Nutr Hosp. 27: 1391-1398.

Dogan Y, Akarsu S, Ustundag B, Yilmaz E, Gurgoze MK (2006). SerumIL-1 $\beta$, IL-2, and IL-6 in Insulin-Dependent Diabetic Children. Mediators of Inflammation. 2006: 1-6.

Erbagci AB, Tarakcioglu M, Coskun Y, Sivasli E, Sibel Namiduru E (2001). Mediators of inflammation in children with typel diabetes mellitus: cytokines in type I diabetic children. Clinical Biochemistry. 34: 645-650.

Fawwad A, Sabir R, Riaz M, Basit A (2014). Uropathogens and the Antimicrobial Susceptibility Patterns in Patients with Type 2 Diabetes. Austin J Endocrinol Diabetes. 1(5): 4

Flaws B, Kuchinski LM and Casanas R ( 2002). The treatment of Diabetes Mellitus with Chinese medicine: A textbook and clinical manual.

Franz M and Horl WH (1999). Common errors in diagnosis and managment of urinary tract infection. I: pathophysiology and diagnosistic technique. Nephrol Dial Transplant. 14:2746-2753.

Gabay C (2006). Interleukin-6 and chronic inflammation. Arthritis Research \& Therapy. 8 (Suppl 2):S3.

Guzmán C, Hallal-Calleros C, López-Griego C, Morales-Montor J (2010). Interleukin-6: A Cytokine with a Pleiotropic Role in the Neuroimmunoendocrine Network. The Open Neuroendocrinology Journal. 3: 152-160.

Haryniewicz K, Szczypa K, Sulikowska A, Jankowskik, Betlejewska K and Hryniewicz W (2001). Antibiotic susceptibility of bacterial strains isolated from urinary tract infections in Poland. J Antimicrob Ther 47: 773-780.

Hirji I, Guo Z, Andersson SW, Hammar N and Caminero AG (2012a). Incidence of urinary tract infection among patient with type 2 diabetes in the UK general practice and research database (GPRD) J Diabetes Complicat. 26: 513-516.

Hirji I, Guo Z, Andersson SW, Hammar N and Caminero AG (2012b). Incidence of genital among patients with tye 2 diabetes in UK 
general practice and research database. J Diabetes Complicat. 26: $501-505$

Jain SK and McVie R (1999). Hyperketonemia can increase lipid peroxidation and lower glutathione levels in human erythrocytes in vitro and in type 1 diabetic patients. Diabetes. 48: 1850-1855.

Jain SK, Kannan K, Lim G, Matthews-Greer J, McVie R and Bocchini JA (2003). Elevated blood interleukin-6 levels in hyperketonemic type 1 diabetic patients and secretion by acetoacetatetreated cultured U937 monocytes. Diabetes Care. 26: 2139-2143.

Javed F, Ahmed A (2013). Proinflammatory Cytokines in the Saliva, Gingival Crevicular Fluid and Serum of Diabetic Patients with Periodontal Disease. J. of Res. and Practice in Dentistry. 2013: Article ID 956990.

Joshi N, Caputo GM, Weitekamp M, Karchmer MW (1999). Infections in patients with diabetes mellitus. N Engl J Med. 341: 1906-12.

King P, Peacock I, Donnelly R (1999). The UK Prospective Diabetes Study (UKPDS): clinical and therapeutic implications for type 2 diabetes. Br J Clin Pharmacol. 48: 643-648.

Khadka KS, Khadka J, Lekhak B, Shrestha P, Tiwari BR (2012). Incidence of urinary tract infection among the patients visiting western regional hospital, Pokhara, Nepal. JHAS 2: 35-37.

Kline KA, Nielsen HV, Sakinc T, Gatermann S (2010). Characterization of a novel murine model of Staphylococcus saprophyticusurinary tract infection reveals roles for Ssp and Sdrl in virulence. Infect. Immun. 78: 1943-1951.

Koul PB (2009). Diabetic Ketoacidosis: A Current Appraisal of Pathophysiology and Management. Clinical Pediatrics . 48: 135144.

Lee MH, park JW (1995). Lipid peroxidation products mediated damage of superoxide dismutase. Biochem Mol Biol Int. 35: 1093-1102.

Longdoh NA, Assob Nguedia JC, Nsagha SD, Nde PF, Fouamo Kamga HC, Nkume AF, Emmanuel TK (2013). Uropathogens from diabetic patients with asymptomatic bacteriuria and urinary tract infections. The West London Med. J. 5: 7-14.

Maedler K, Dharmadhikari G, Schumann DM, Størling J (2009). Interleukin-1 beta targeted therapy for type 2 diabetes. Expert Opin Biol Ther. 9: 1177-88.

Mandrup-Poulsen T, Pickersgill L, Yves Donath M (2010). Blockade of interleukin 1 in Type 1 diabetes mellitus. Nature Reviews Endocrinology. 6: 158-166.

Mokaddas EM, Sanyal SC (1999). Resistance patterns of Pseudomonas aeruginosa to carbapenems and piperacillin/tazobactam. J Chemother. 11: 93-6.

Moussa SA (2008). Oxidative stress in Diabetes Mellitus. Romanian J Biophys. 18: 225-236.

Nagamatsu K, Hannan TJ, Jana B, Guest RL (2015). Dysregulation of Escherichia coli $\alpha$-hemolysin expression alters the course of acute and persistent urinary tract infection. Proc. Natl Acad. Sci. USA. 112: E871-E880.

Nielsen HV, Kline KA, Nielsen HV, Kau AL, Flores-Mireles AL (2013). Pilin and sortase residues critical for endocarditis- and biofilmassociated pilus biogenesis in Enterococcus faecalis. J. Bacteriol. 195: 4484-4495.

Poretsky L (2002). Principles of diabetes mellitus. (2nd Ed.)

Prakash S, Sudha S (2012). Lipid peroxidation and antioxidant status in south indian patients with type 2 diabetes mellitus. international research journal of pharmacy. 3: 132-134.
Ramana BV, Chaudhury A (2012). Prevalence of uropathogens in diabetic patients and their resistance pattern at a tertiary care centre in south India. Int J Biol Med Res. 3: 1433-1435.

Rudy M, Nowakowska M, Wiechuła B, Zientara M, RadoszKomoniewska H (2004). Antibiotic susceptibility analysis of Enterococcus spp. isolated from urine. Przegl Lek. 6: 473-476.

Sahm DF, Thornsberry C, Mayfield DC, Jones ME, Karlowsky JA (2001). Multidrug- resistant urinary tract isolates of escherichia coli: Prevalence and Patient Demographics in the United States in 2000. Antimicrobial agents and chemotherapy. 45: 1402-1406 .

Saleem M, Daniel B (2011). Prevalence of urinary tract infection among patients with diabetes in Bangalore city. Int J. Emerg. Sci. 1: 133142.

Santhanam U, Ray A, Sehgal PB (2003). Repression of the interleukin 6 gene promoter by p53 and the retinoblastoma susceptibility gene product. Proc Natl Acad Sci. 88: 7605-7609.

Simkhada R (2013). Urinary tract infection and antibiotic sensitivity pattern among diabetics. Nepal Med Coll J. 15: 1-4.

Stewart C (2006). Guidelines for the ED management of pediatric patients ketacidosis (DKA).Emergency Medicine Practice. 3(3).

Stratton IM, Adler Al, Neil Haw (2000). Association of glycaemia with macrovascular and microvascular complications of Type 2 diabetes (UKPDS 35): prospective observational study. BMJ. 321: 405-412.

Tchorzewski H, Glowacka E, Banasik M, Lewkowicz P, SzalapskaZawodniak M (2001). Activated T lymphocytes from patients with high risk of type I diabetes mellitus have different ability to produce interferon-gamma, interleukin- 6 and interleukin- 10 and undergo antiCD95 induced apoptosis after insulin stimulation. Immunology Letters.75: 225-234.

Umpierrez GE, Khajavi M, Kitabchi AE (1996). Diabetic ketoacidosis and hyperglycemic hyperosmolar syndrome. Am J Med Sci 311: 225-233.

Vaziri ND, Dicus M, Ho ND, Boroujerdi-rad L, Sindhu RK (2003). Oxidative stress and dysregulation of superoxide dismutase and NADPH oxidase in renal insufficiency. Kidney International. 63: 179-185.

Wegner M, Araszkiewicz A, Piorunska-Stolzmann M, Wierusz-Wysocka B, Zozulinska-Ziolkiewicz D (2013). Association Between IL-6 Concentration and Diabetes-Related. Variables in DM1 Patients with and without Microvascular Complications. Inflammation. 36: 723-728.

Wellen KE, Hotamisligil GS (2005). Inflammation, stress, and diabetes. J Clin Invest. 115: 1111-1119

Zhanel GG, Laing NM, Nichol KA, Palatnick LP, Noreddin A, Hisanaga T, Johnson JL, the NAVRESS Group, Hoban DJ (2003). Antibiotic activity against urinary tract infection (UTI) isolates of vancomycinresistant enterococci (VRE): results from the 2002 North American Vancomycin Resistant Enterococci Susceptibility Study (NAVRESS). J. of Antimicrobial Chemotherapy. 52: 382-388. 